ISSN 1112-9867

Available online at http://www.jfas.info

\title{
CLASSIFICATION OF ENHANCED OIL RECOVERY METHODS BY LITHOLOGY
}

\author{
M. Foroozanfar
}

School of Petroleum Engineering, University of Tehran, Kish International Campus , Iran

Published online: 05 June 2016

\begin{abstract}
Rich Zagros basin of hydrocarbon bearing structures in the Middle East has led to a number of oil and gas reservoirs in Iran are shared with neighboring countries. The reservoirs are integrated in geology, and in terms of property are communal. Border competition between neighboring countries has caused the shared reservoirs be in the top attention. In addition, Iran's largest oil and gas reservoirs are located in political boundaries. Therefore, a better understanding of the reservoir makes better use of them. In this article classified EOR methods base on lithology of the reservoirs and investigated the frequent EOR method (gas injection) in the carbonate reservoir that is the most reservoir lithology in Iran, gas has low viscosity and due to this property we need some complementary methods like foam flooding to overcome this disadvantage.
\end{abstract}

Keywords: lithology; carbonate; gas injection; foam flooding.

Author Correspondence, e-mail: $\underline{\text { m.foroozanfar@ut.ac.ir }}$

doi: http://dx.doi.org/10.4314/jfas.8vi2s.18

\section{INTRODUCTION}

With the decline in oil discoveries during the last decades it is believed that EOR technologies will play a key role to meet the energy demand in years to come. Most of the current world oil production comes from mature fields. Increasing oil recovery from the aging resources is a major concern for oil companies and authority's .Therefore, the increase of the recovery factors from mature fields under primary and secondary production will be critical to meet the growing energy demand in the coming years. 
Improved Oil Recovery (IOR) methods encompass Enhanced Oil Recovery (EOR) methods as well as new drilling and well technologies, intelligent reservoir management and control, advanced reservoir monitoring techniques and the application of different enhancements of primary and secondary recovery processes. It is well known that EOR project have been strongly influenced by economics and crude oil prices. The initiation of EOR projects depends on the preparedness and willingness of investors to manage EOR risk and economic exposure and the availability of more attractive investment options.

\section{ENHANCED OIL RECOVERY BY LITHOLOGY}

Reservoir lithology is one of the screening considerations for EOR methods, often limiting the applicability of specific EOR methods. Figure 1 show that most EOR applications have been in sandstone reservoirs, as derived from a collection of 1,507 international EOR projects in a database consolidate by the authors during the last decade. From figure one, it is clear that EOR thermal and chemical projects are the most frequently used in sandstone reservoirs compared to other lithologies.

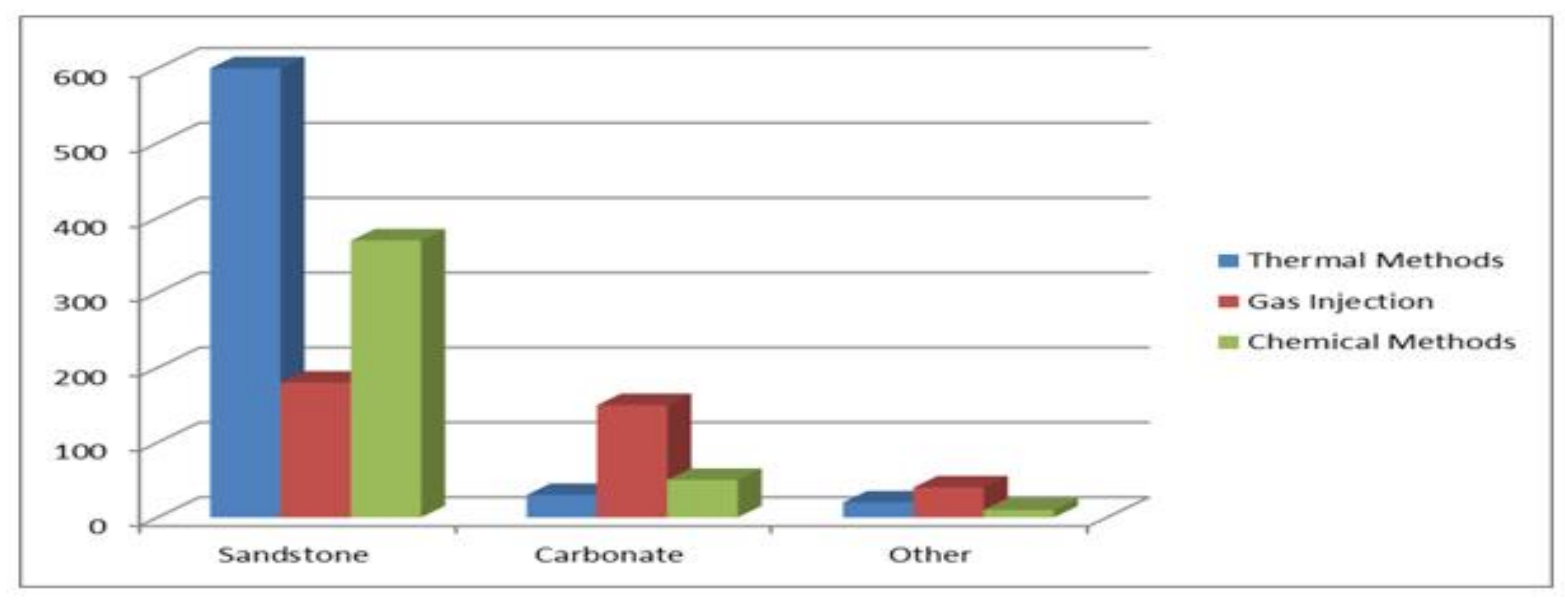

Fig.1. EOR methods by lithology

\subsection{EOR in sandstone formation}

It is well known that EOR methods have been extensively implemented in sandstone formations. In general, sandstone reservoirs show the highest potential to implement EOR projects because most of the technologies have been tested at pilot and commercial scale in this type of lithology. Additionally, there are some fields where different EOR technologies have been evaluated successfully at pilot scale demonstrating technical applicability of EOR methods in the same field. Buracica and Carmopolis (Brazil), and Karazhanbas (Kazakhstan) 
are good field examples that have been subjected to several EOR technologies at pilot scale in sandstone formation .

\subsubsection{Thermal methods}

Cyclic steam injection (Huff \& Puff), steam flooding and most recently Steam-Assisted Gravity Drainage (SAGD) have been the most widely used methods of heavy and extra-heavy oil production in sandstone reservoirs during last decades. Thermal EOR projects have been concentrated mostly in Canada, U.S, Brazil and China. Steam injection began approximately 5 decades ago. Steam injection has also been tested in medium and light oil reservoir being crude oil distillation and thermal expansion the main recovery mechanisms in these types of reservoirs. However, steam injection in medium and light oil reservoirs has not contributed to EOR production worldwide.

Steam Assisted Gravity Drainage (SAGD) represents another important EOR thermal to increase oil production in oil sands. Due to SAGD applicability in unconsolidated reservoirs with high vertical permeability, this EOR method has received attention in countries with heavy and extra-heavy oil resources, especially Canada and Venezuela.

In-situ combustion (ISC) has been the second most important recovery method for heavy crude oils in the past decades. Despite its long history and some commercial successes, this EOR processes has not been fully accepted among operators due to excessive number of inconclusive or failed pilots. However, an important number of failed projects can also be attributed to lack of understanding of the process and applications in reservoirs not necessarily appropriate for this EOR process.

Air injection in light oil reservoirs (referred to as High Air Pressure Injection or HPAI) has gained greater attention during the last decade. This successful application of air injection projects in light oil reservoirs like West Hackberry in the U.S. demonstrate that this recovery process is viable EOR strategy for high dipping angle reservoirs.

Finally, several other approaches of thermal EOR methods have been proposed with none or low impact on oil production. Some of them include downhole steam generation, electrical heating or electromagnetic heating and microwave technologies. However, these technologies have not been proved to be technically and economically feasible compared with traditional EOR thermal methods.

\subsubsection{Chemical methods}

Chemical EOR methods lived their best times in the 1980's, most of them in sandstone reservoirs [1]. The total of active projects peaked in 1986 with polymer flooding as the most important chemical EOR method. However, since 1990's, oil production from chemical EOR 
method has been negligible around the word except for China [2]. Nevertheless, chemical flooding has been shown to be sensitive volatility of oil market despite recent advances and lower cost of chemical additives. Polymer flooding, needs to be considered a mature technology and still be the most important EOR chemical method in sandstone reservoirs based on the review of full-field case histories.

While polymer flooding has been the most applied EOR chemical method in sandstone reservoirs [3], the injection of alkali, surfactant, alkali-polymer (AP), surfactant polymer (SP) and alkali-surfactant-polymer (ASP) have been tested in a limited number of fields. Micellar polymer flooding had been the second most used EOR chemical method in light and medium crude oil reservoirs until the early 1990's [4]. Although this recovery method was considered a promising EOR process since the 1970's, the high concentration and cost of surfactants and co-surfactants, combined with the low oil prices during mid 1980's limited its use. The development of the ASP technology since mid 1980's and the development of the surfactant chemistry have been brought up a renewed attention for chemical floods in recent years , especially to boost oil production in mature and water flooded fields. Therefore and despite the volatility of oil prices, it is fair to conclude that operators and surfactant manufacturers are showing interest in EOR chemical flooding [5]. This trend is also noticed with an increase of screening and lab studies to evaluate or re-estimate EOR potential of chemical flooding in different basins [6].

\subsubsection{Gas methods}

EOR gas flooding has been the most widely used recovery methods of light, condensate and volatile oil reservoirs. Although nitrogen $\left(N_{2}\right)$ injection has been proposed to increase oil recoveries under miscible conditions favoring the vaporization of light fractions of light oils and condensates, today few $N_{2}$ floods are ongoing in sandstone reservoirs . Immiscible $\mathrm{N}_{2}$ floods are reported in Hawkins Field (Texas) and Elk Hills (California) [7]. No new one $\mathrm{N}_{2}$ floods in sandstone reservoirs have been documented in the literature during the last few years and we do not foresee an increment in number of projects implementing this EOR gas flooding method.

On the other hand, $\mathrm{CO} 2$ flooding has been the most widely used EOR recovery method for medium and light oil production in sandstone reservoirs during last decades, especially in the U.S. due to the availability of cheap and readily available $\mathrm{CO} 2$ from natural sources. As can be seen, CO2-EOR has become one of the preferred EOR processes globally and considering $\mathrm{CO} 2$ from natural and industrial sources. 


\subsection{EOR in carbonate formation}

It is well known that a considerable portion of the world's hydrocarbon endowment is in carbonate reservoirs. Carbonate reservoirs usually exhibit low porosity and may be fractured. These two characteristics along with oil-to-mixed wet rock properties usually result in lowered hydrocarbon recovery rates. When EOR strategies are pursued, the injected fluids will likely flow through the fracture network and bypass the oil in the rock matrix. The high permeability in the fracture network and the low equivalent porous volume frequently results in early breakthrough of the injected fluids.

A large number of EOR field projects in carbonate reservoirs have been referenced in the literature during the last decades. Although these field projects demonstrate the technical feasibility of various EOR methods in carbonate reservoirs, gas injection (continuous or in a WAG mode) are still the most common EOR process implemented in this type of lithology. Polymer flooding is the only proven EOR chemical method in carbonate formations while EOR thermal methods have made a relatively small contribution to world's oil production from carbonate reservoirs. However, High Pressure Air Injection (HPAI) projects have been steadily increasing in recent years, especially in light oil carbonate reservoirs in the U.S. [8].

\subsubsection{Thermal methods}

Thermal EOR projects have not been popular in carbonate formations. Neither cyclic nor continuous steam injection has been widely used in carbonate reservoirs. Steam injection in carbonates has been mostly tested at small scale and only Qarn Alam Field in Oman is announcing full field steam flooding operations. Therefore, steam injection in Qarn Alam Field will contribute to define the future of steam injection in carbonate formations. SAGD is another technology that has been proposed for carbonate reservoirs [9]. A very limited number of studies are considering this recovery process for fractured carbonate reservoirs. The fractured and vuggy nature of carbonate formations can cause uneven sweeping along SAGD well pairs. This may lead to irregular steam chambers development causing the early breakthrough of steam into the horizontal producer, resulting in low recovery factors, and therefore uneconomic projects. On the other hand, air injection projects in carbonate formations have shown a steady increase since 2000, especially HPAI projects in U.S. light oil reservoirs. There is no doubt that risk perception of air injection processes is still part of our industry. However, actual HPAI projects in U.S. carbonate reservoirs demonstrate that risks can be controlled and this process is economically attractive. Mexico is one example of countries evaluating air injection processes in naturally fractured carbonates given that most of its production and reserves are coming from this type of reservoirs. 


\subsubsection{Chemical methods}

Polymer flooding is the only proven chemical EOR technology, mostly at early stages of water flooding, in carbonate reservoirs. However, carbonate reservoirs have made a relatively small contribution to polymer flooding in terms of total oil recovered in the U.S. [10]. With today's technology, Alkali-Polymer (AP) and Alkali-Surfactant-Polymer (ASP) floods are applicable to sandstone reservoirs only. However, surfactant-polymer (SP) seems to be a feasible recovery process in both carbonate (e.g., Midland Farm Unit, Texas) and sandstone reservoirs. As of date, no chemical flooding other than polymer-flooding field in carbonate reservoirs have been reported in the literature reviewed.

Surfactant injection is the only chemical method used recently as a well stimulation and wettability modification of carbonate reservoirs. In fractured reservoirs, spontaneous water imbibitions can occur from the rock matrix into fractures. Subsequently, this mechanism leads to oil drainage from the matrix towards the fracture network, making surfactants attractive to improve oil recovery in oil-wet carbonate reservoirs by changing rock wettability (to mixed/water wet) and promoting the imbibition process.

Based on the present status of the technology, chemical EOR methods are not expected to make an important contribution in oil production from carbonate reservoirs during the next one or two decades.

\subsubsection{Gas methods}

EOR gas flooding has been the most widely used recovery methods of light, condensate and volatile oil carbonate reservoirs. Gas injection have been the EOR method most frequently applied in carbonate formations compared to EOR chemical and thermal methods. N2 flooding has been an effective recovery process for deep, high-pressure, and light oil reservoirs. Generally for these types of reservoirs, N2 flooding can reach miscible conditions. However, immiscible N2 injection has also been used for pressure maintenance, cycling of condensate reservoirs, and as a drive gas for miscible slugs [10].

If there is no other way to monetize natural gas, then a more practical use of natural gas would be to use it in pressure maintenance projects or in WAG processes while new business opportunities become available. This development strategy will contribute to preserve reservoir energy maximizing oil recovery with an upside potential of monetizing natural gas through reservoir depressurization strategies implemented or proposed in the North Sea [11]. CO2-EOR has been successfully implemented in both mature and waterflooded carbonate reservoirs [10]. CO2 flooding from natural sources has been the most important EOR process in the U.S. and particularly in carbonate reservoirs of the Permian Basin. The popularity of 
$\mathrm{CO} 2$ projects is closely related to the abundant availability of natural sources of $\mathrm{CO} 2$ and associated CO2 transporting pipelines that are generally located close to the oilfields [10]. Finally and most recently, Saudi Aramco announced its plans to inject CO2 as an EOR and storage strategy at the giant Ghawar field. This strategy not only will contribute to reduce emissions but will also increase natural gas availability for power generation [12].

In today's world addressing CO2-EOR projects almost always inevitably links these projects to topics such as climate change. Climate change has become an issue of intense discussion over the last decade. Despite strong debate within the scientific community as to whether or not global warming is linked to population growth and industrial development, the international community is proactively trying to secure resources to meet future energy demands while simultaneously restricting $\mathrm{CO} 2$ and other greenhouse gas emissions generated by current energy production [13].

The fundamental reason why $\mathrm{CO} 2$ storage combined with EOR has become the preferred emission reduction strategy is because high hydrocarbon price scenarios provide the necessary financial incentive for increasing oil and gas reserves through EOR methods and also generates the capital needed to fund such projects until proper regulatory framework is in place [12].

\subsubsection{The predominant reservoir lithology in Iran is carbonate and according to the figure 1 the appropriate method for this lithology is gas injection.}

The injection of $\mathrm{Co}_{2}$ for the enhanced oil recovery causes lower injectivity problems due to its higher viscosity, compared to the other common injection. Also, the lower formation volume factor (FVF) of $\mathrm{Co}_{2}$ and lower mobility ratio make the volumetric efficiency higher for $\mathrm{Co}_{2}$ than other solvents.

The $\mathrm{Co}_{2}$ density is much closer to typical light oil density (under miscible conditions) than most of the other solvent injectants at the reservoir conditions, making $\mathrm{Co}_{2}$ less prone to gravity segregation compared to $\mathrm{N}_{2}$ and $\mathrm{CH}_{4}$ under similar pressure.

Another beneficial effect of $\mathrm{Co}_{2}$ is the likelihood of higher gravity segregation in high water saturation zones of the reservoir than in the higher oil saturation zones. This effect is also useful to target pockets and bypassed areas of oil and drain them effectively.

Considering high solubility, about 700-800 Scf/bbl (Holm and Josendal , 1974) and the wide range of suitability in the hydrocarbon reservoirs compared to other gas injectants, Co2 has potential to replace the expensive hydrocarbon (C2 - C3 ) injection gases (Novosad , 1996) . Once injected in the target zone, Co2 develops mutual solubility to form a single, 
homogeneous phase, leading to swelling of the reservoir oil. This results in the oil viscosity reduction and the water viscosity rise. This favorably improves the mobility ratio of the EOR process.

The most disadvantage of gas injection is low density and high mobility ratio of gas that cause viscous displacement and reduce volumetric efficiency, to overcome this disadvantage we need to inject foam.

\section{FOAM MODEL}

Foam can be used in a number of ways to increase the production from an oil reservoir. The foam acts to decrease the mobility of gas; this effect can be used to slow the breakthrough of injected gas or to reduce the production of gas cap gas.

A foam is generated by adding a surfactant to an aqueous phase, and passing a gas through the surfactant to generate a stable dispersion of gas bubbles in the liquid. The foam can be transported with the gas flow into the reservoir. The major beneficial effect of the foam is to reduce the mobility of the gas. Note that in foam flooding the reduction of the interfacial tension (between oil and water) is not a significant effect. The reduction of gas mobility typically depends on a range of factors including pressure and shear rate.

The foam stability has a major effect on the usefulness of foam injection. Typically the foam suffers from adsorption on to the rock matrix, decay over time, and enhanced decay in the presence of water.

The physics of the foam flooding process is in general very complex. For example, when foam bubbles form in a porous medium the bubble size typically fills the pore size of the rock matrix. These bubbles tend not to move until they are compressed (hence reducing their size) by applying a higher pressure. Then in turn more bubbles are generated at the new higher pressure, but with the original bubble size.

The adsorption of foam is assumed to be instantaneous, and the quantity adsorbed is a function of the active foam concentration.

Mass of adsorbed foam $=\mathrm{V} \cdot\left(\frac{1-\emptyset}{\emptyset}\right) \cdot \rho_{r} \cdot C A\left(C_{\text {foam }}\right)$

Where

$\mathrm{V}:$ is the pore volume of the cell,

$\emptyset:$ is the porosity ,

$\rho_{r}:$ is the mass density of the rock,

$\mathrm{CA}\left(\mathrm{C}_{\text {foam }}\right)$ : is the adsorption isotherm as a function of local foam concentration in solution , 


\subsection{Foam decay}

Foam effectiveness will typically reduce over time, even in conditions very favorable to foam stability. This reduction in effectiveness may be accelerated in the presence of water or oil. The reduction in foam effectiveness over time is modeled by foam decay; the half-life of the decay can be a function of both oil and water saturation. If the decay half-life is a function of both oil and water saturation, the foam is assumed to decay with the minimum half-life.

\subsection{Gas mobility reduction}

The foam modifies the gas mobility by way of a simple multiplier supplied as a function of foam concentration (that is the effective surfactant concentration).

Unmodified gas flow : $f_{g}=\frac{K_{r g}}{\mu_{g} B_{g}}(T \cdot D P)$

Modifiec flov : $f_{g m}=M\left(C_{\text {foam }}\right) \frac{K_{r g}}{\mu_{g} B_{g}}(T . D P)=M\left(C_{\text {foam }}\right) f_{g}$

Where

$K_{r g}:$ is the gas relative permeability,

$\mu_{g}:$ is the gas viscosity,

$B_{g}$ : is the gas formation volume factor,

$\mathrm{T}:$ is the transmissibility,

$\mathrm{DP}:$ is the potential difference,

$M\left(C_{\text {foam }}\right):$ is the input mobility reduction factor,

$C_{\text {foam }}:$ is the foam concentration,

The mobility reduction factor $M\left(C_{\text {foam }}\right)$ can optionally be influenced by two separate effects, both of which will tend to increase (that is to increase the gas mobility again). $M\left(C_{\text {foam }}\right)$ can be varied as a function of both pressure and shear rate.

The mobility reduction factor including the pressure effect is:

$M=\left(1-M\left(C_{\text {foam }}\right)\right) M_{P}(P)+M\left(C_{\text {foam }}\right)$

Where

MP : is the mobility reduction factor with the pressure effect,

$M\left(C_{\text {foam }}\right):$ is the original reduction factor as a function of foam concentration,

$M_{P}(P):$ is the pressure dependency function,

$\mathrm{P}:$ is the oil pressure,

The mobility reduction factor including the shear effect is:

$M F=(1-M) M_{S}(V)+M P$ 
Where

MF : is the final mobility reduction factor,

MP : is the mobility reduction factor after applying the pressure effect,

$M_{S}(V)$ : is the shear dependency function,

$\mathrm{V}:$ is gas velocity,

The gas velocity is calculated as:

$V=B_{g}\left(\frac{f_{g}}{\emptyset \cdot A}\right)$

Where

$f_{g}:$ is the gas flow rate in surface units,

$B_{g}$ : is gas formation volume factor,

$\emptyset:$ is the average porosity of two cells ,

A : is the flow area between the two cells,

\section{SIMULATION}

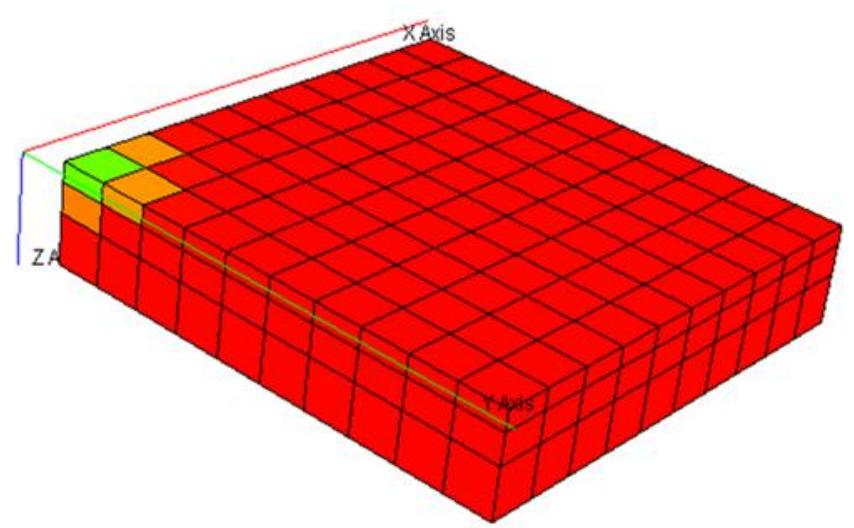

Fig.2. 3D View of the Reservoir

In this simulation investigated some effective parameter on foam flooding such as:

- The mass density of rock type at reservoir conditions.

- Foam decay data as a function of oil saturation.

- $\quad$ Pressure dependence of foam mobility reduction.

- Shear dependence of foam mobility reduction.

- $\quad$ Foam concentration for injection wells. 


\section{RESULTS}

\subsection{The mass density of rock type at reservoir conditions}

This factor is used in the calculation of the foam loss due to adsorption.

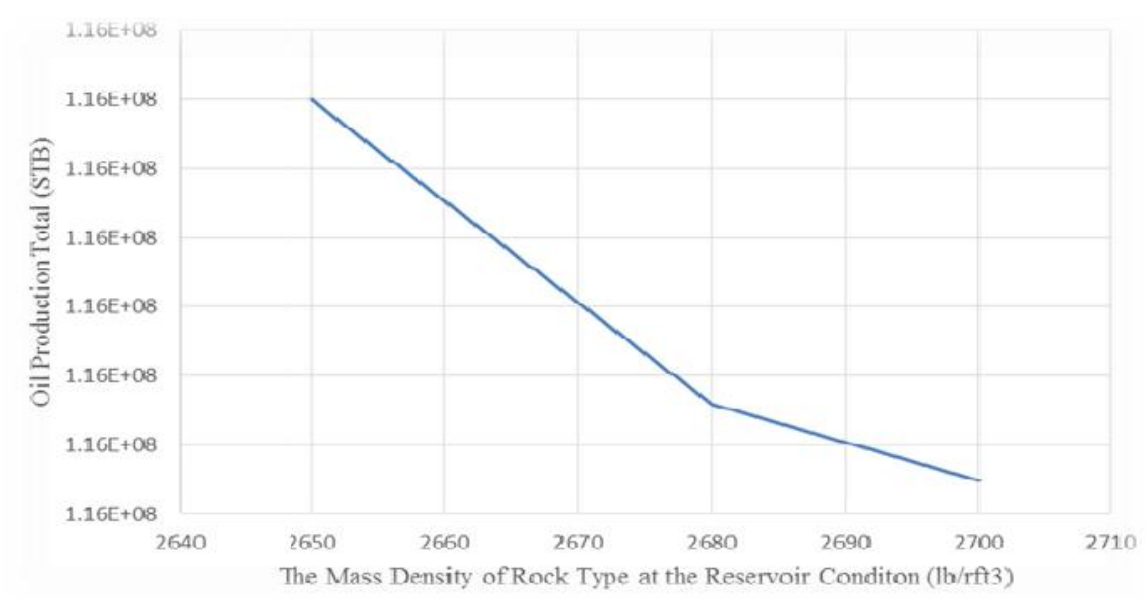

Fig.3. Effect of mass density of rock (lb/rft3) on oil recovery (STB) in foam injection

\subsection{Foam decay data as a function of oil saturation}

This factor describes the decay of foam as a function of oil saturation.

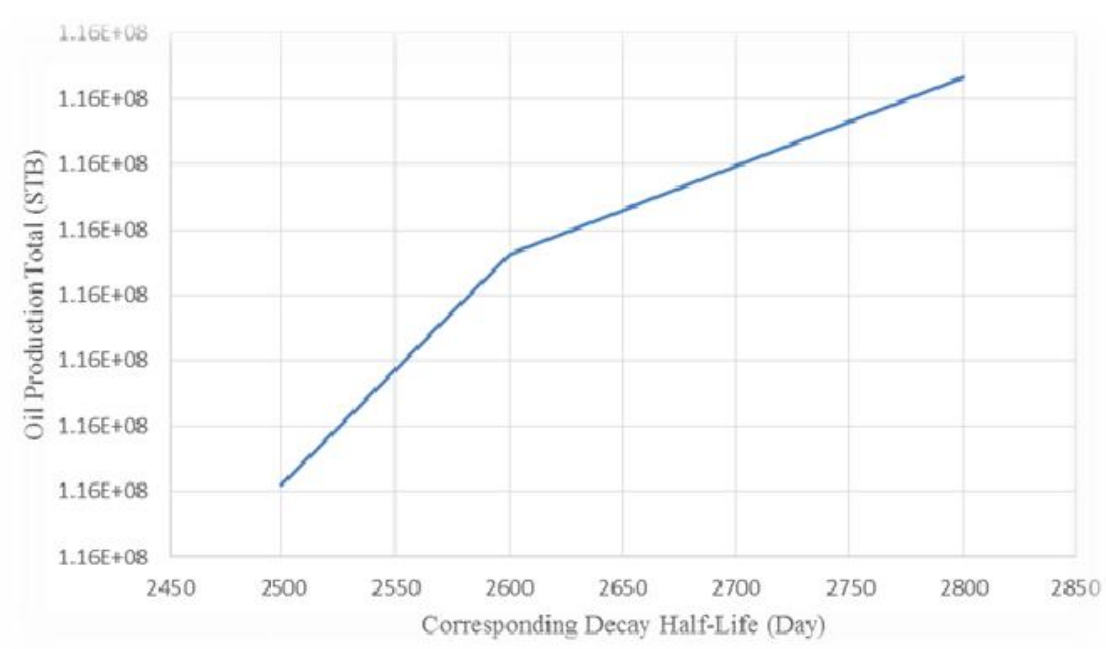

Fig.4. Effect of foam decay as a function of oil saturation half-life (days) on oil recovery in foam injection

\subsection{Pressure dependence on foam mobility reduction}

This factor is used to describe the pressure dependence of the foam mobility reduction factor. 


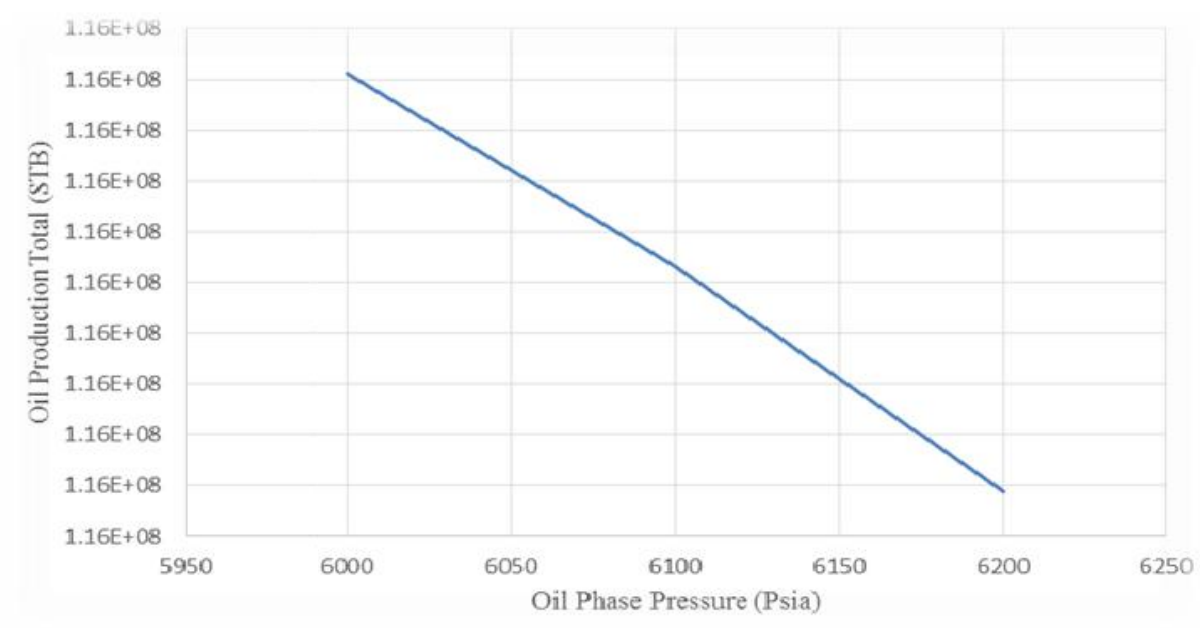

Fig.5. Effect of oil phase pressure (Psia) on oil recovery in foam injection

\subsection{Shear dependence of foam mobility reduction}

This factor describes the shear dependence of the foam mobility reduction.

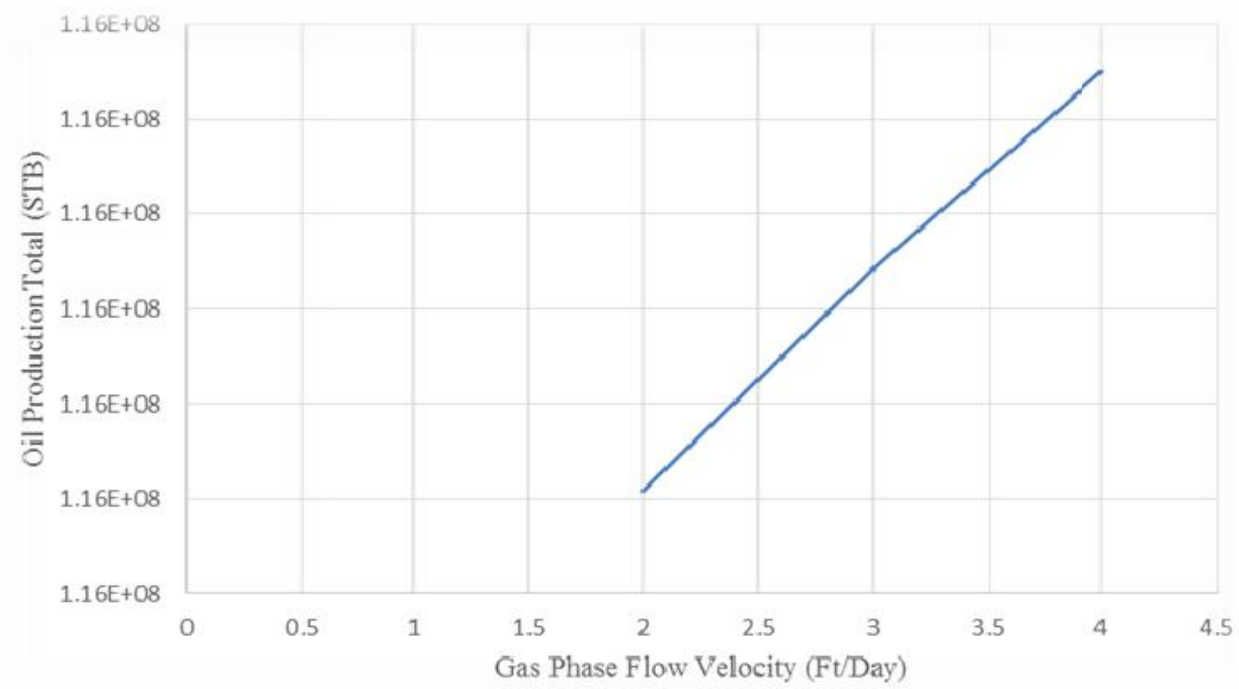

Fig.6. Effect of gas phase velocity (ft/day) on oil recovery (STB) in foam injection 


\subsection{Foam concentration for injection wells}

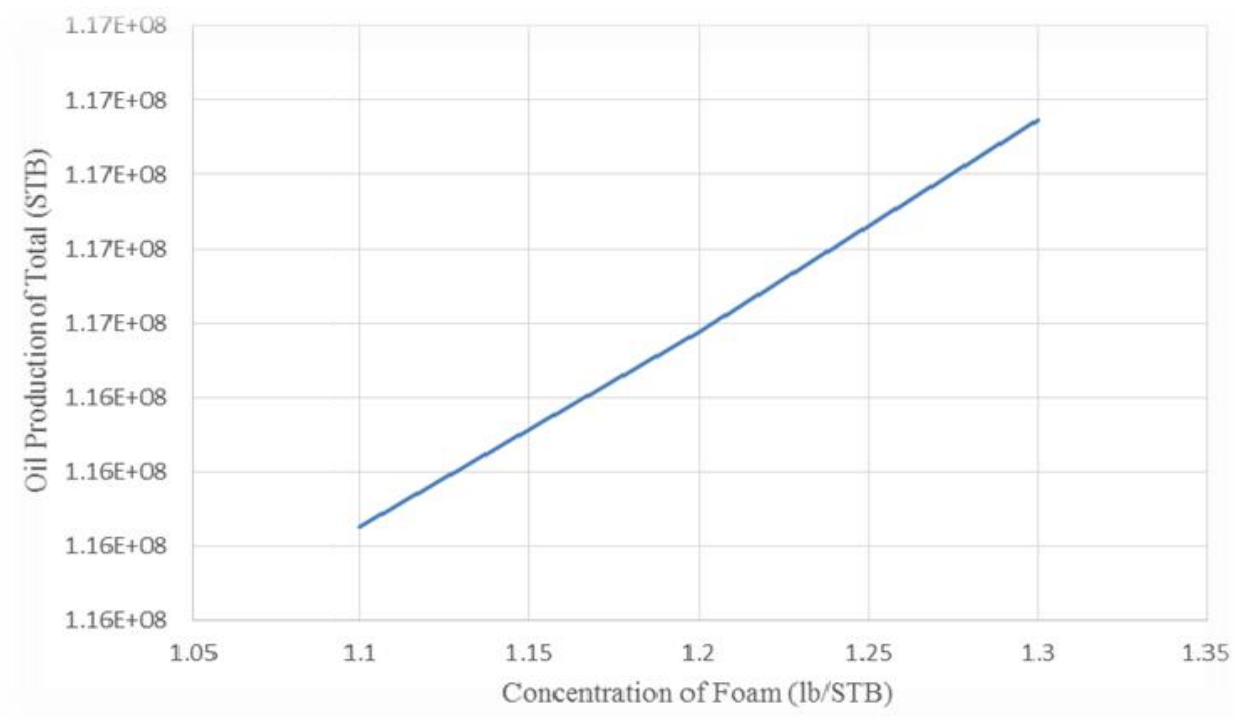

Fig.7. Effect of concentration of foam (lb/STB) in injection well on oil recovery in foam injection

\section{CONCLUSION}

According to the figure 1, the appropriate way to enhance oil recovery from carbonate reservoirs is gas injection. Gas due to low density and high mobility ratio cause to decrease microscopic displacement efficiency. High mobility ratios cause poor displacement and sweep efficiencies, which can be caused by a large viscosity contrast between the displacing fluid (i.e. water) and oil or by the presence of high permeability flow channels that result in early breakthrough of the displacing fluid (i.e. water) at the producer well (Lyons \& Plisga , 2005). Foams can be used in a number of ways to increase the production from the oil reservoirs. The foam acts to decrease the mobility of gas; this effect can be used to slow the breakthrough of the injected gas or to reduce the production of gas-cap gas.

\section{REFERENCES}

[1] Needham, R.B.; Doe, P.H. Polymer Flooding Review. J. Pet. Technol, 1987, 39, 15031507.

[2] Han, D.K.; Yang, C.Z.; Zhang, Z.Q.; Lou, Z.H.; Chang, Y.I. Recent development of enhanced oil recovery in China. J. Pet. Sci. Eng, 1999, 22, 181-188.

[3] Manning, R.K.; Pope, G.A.; Lake, L.W.; Paul, G.W.; Wesson, T.C. A Technical Survey of Polymer Flooding Projects; Report No. DOE/BC/10327-19; U.S. Department of Energy: Tulsa, OK, USA, 1983; 329. 
[4] Lowry, P.H.; Ferrell, H.H.; Dauben, D.L. A Review and Statistical Analysis of MicellarPolymer Field Test Data National Petroleum Technology Office; Report No. DOE/BC/10830-4; U.S. Department of Energy: Tulsa, OK, USA, 1986.

[5] Fletcher, A.J.P.; Morrison, G.R. Developing a Chemical EOR Pilot Strategy for a Complex, Low Permeability Water Flood (SPE-112793). In Proceedings of SPE/DOE Symposium on Improved Oil Recovery, Tulsa, OK, USA, 20-23 April 2008.

[6] Moritis, G. 2008 Worldwide EOR Survey. Oil Gas J. 2008, 106, 41-42, 44-59.

[7] Manrique, E. Enhanced Oil Recovery (EOR): Trends, Risks, and Rewards. Presented at the ACI Optimising EOR Strategy 2009, London, UK, 11-12 March, 2009.

[8] Sedaee, B.; Rashidi, F. Application of the SAGD to an Iranian Carbonate Heavy-Oil Reservoir (SPE-100533). In Proceedings of SPE Western Regional/AAPG Pacific Section/GSA Cordilleran Section Joint Meeting, Anchorage, Alaska, 8-10 May 2006.

[9] Manrique, E.J.; Muci, V.E.; Gurfinkel, M.E. EOR Field Experiences in Carbonate Reservoirs in the United States. SPE Reserv. Eval. Eng. 2007, 10, 667-686.

[10]Boge, R.; Lien, S.K.; Gjesdal, A.; Hansen, A.G. Turning a North Sea Oil Giant Into a Gas Field-Depressurization of The Statfjord Field (SPE-96403), Offshore Europe: Aberdeen, U.K., 6-9 September 2005.

[11] Hamilton, G. Strategies for CO2 Reductions in the U.S. Enhanced Oil Recovery Production Segment: Utilizing Energy Efficiency as the First Step (SPE-121003). In Proceedings of SPE Americas E\&P Environmental and Safety Conference, San Antonio, TX, USA, 23-25 March, 2009.

[12] Vladimir Alvarado and Eduardo Manrique, "Enhanced Oil Recovery: An Update Review" , Department of Chemical and Petroleum Engineering, University of Wyoming, Department 3295, 1000 E. University Ave, Laramie, WY, USA .

[13] Crowe, C. M. and Nishio, M. Convergence Promotion in the Simulation of Chemical Processes - The General Dominant Eigenvalue Method.

\section{How to cite this article:}

Foroozanfar M. Classification of enhanced oil recovery methods by lithology. J. Fundam. Appl. Sci., 2016, 8(2S), 228-241. 